\title{
X-RAY TOMOGRAPHIC PICTURE OF HODGKIN'S DISEASE
}

\section{РЕНТГЕНО-ТОМОГРАФИЧЕСКАЯ КАРТИНА БОЛЕЗНИ ХОДЖКИНА}

\author{
Viktor Sokolov ${ }^{1}$ \\ Alexander Korsun ${ }^{2}$
}

DOI: https://doi.org/10.30525/978-9934-588-53-2-49

\begin{abstract}
Described for the first in 1832, Hodgkin's lymphoma represents $4 \%$ of all newly diagnosed malignant tumors in Ukraine. The incidence rate is 2.4 per 100,000 population / year and constitutes $1 \%$ of all malignant neoplasms. The incidence rate is higher in men (1.4: 1) and two peaks of morbidity of aged 15-30 and older than 55 are recorded. AIDS patients are 8 times more prone to disease. Lymphogranulomatosis (LGM) is an intermediary between cancer in non-infected patients and systemic blood diseases, therefore requires a special approach in treatment. In recent years clinical medicine has had remarkable success in treating patients with close illnesses; but the results of treatment depend largely on early diagnosis. If the disease is detected at an early stage, a complete cure is possible.

The main objectives of CT studies in the prevention, diagnosis and treatment of lymphoproliferative diseases:

1. Primary diagnosis of isolated forms;

2. Stages 1 to 4 [2] (B-systemic symptoms, E-extranodal lesion);

3. Evaluation of treatment results;

4. Control of relapses;

5. Monitoring the state of residual mass.

Most affected with Hodgkin's lymphoma are the mediastinal lymph nodes $(60 \%)$, less commonly are cervical, bronchopulmonary $(20 \%)$ and at hilum.
\end{abstract}

\footnotetext{
${ }^{1}$ Professor, Chief Department of Radiation Diagnostics, Therapy and radiation Medicine,

Odessa National Medical University, Ukraine

${ }^{2}$ Assistant Professor, Department of Radiation Diagnostics,

Therapy and radiation Medicine,

Odessa National Medical University, Ukraine
} 
We conducted a study to identify the primary location of the lesion and determine its involvement in the pathological process in 156 patients with HL. The mean age of the patients was 60 . Studies have been conducted with a duration of the disease of several months to 10 years. The stages of the disease have been evaluated according to the principles of international classification.

The studies were conducted using "Toshiba Asteion Super-4" 4-slice computed tomography scanner, "Toshiba Aquilion 64" 64-slice CT scanner, "Philips Intera 1,5T" MRI. In nearly all patients, the data obtained have been confirmed. In all patients, abdominal organs and retroperitoneal space were examined. Examinations were repeatedly conducted: before and after chemoradiotherapy. In most patients, the diagnoses were histologically confirmed.

\section{1. Вступление}

Впервые описанная в 1832 г. лимфома Ходжкина составляет 4\% среди всех впервые выявляемых злокачественных опухолей в Украине. Частота заболеваемости 2,4 на 100000 населения/год и составляет $1 \%$ всех злокачественных новообразований. Мужчины болеют чаще $(1,4: 1)$ и существует два пика заболеваемости возраст 15-30 и старше 55 лет. Пациенты, пациенты со СПИДом, заболевают в 8 раз чаще. Лимфогранулематоз (ЛГМ) занимает промежуточное положение между раком у не инфицированных пациентов[1] и системными болезнями крови и требует особого подхода к лечению. Клиническая медицина в последние годы добилась выдающихся успехов в области лечения больных с подобными заболеваниями, однако результаты лечения в значительной мере зависят от ранней диагностики. При выявлении заболевания на ранней стадии возможно полное излечение.

Основные задачи КТ исследований в профилактике, диагностике и лечении лимфопролиферативных заболеваний:

1.Первичная диагностика изолированных форм.

2. Стадирование 1-4 [2] (В-системные симптомы, Е-экстранодальное поражение).

3. Оценка результатов лечения.

4. Контроль рецидивов.

5. Контроль состояния остаточных масс. 
По данным литературы [3], при лимфоме Ходжкина Наиболее часто поражаются лимфатические узлы медиастинальные (60\%), шейные, реже бронхопульмональные (20\%) и корневые.

Нами было проведено исследование для выявления первичной локализации поражения и определение его вовлечения в патологический процесс у 156 больных с НХЗЛ. Средний возраст обследованных пациентов 60. Исследования были проведены с длительностью заболевания от нескольких месяцев до 10 лет. Стадии заболевания оценивалась по принципам международной классификации [2].

Исследования были проведены на 4-х срезовом компьютерном томографе Toshiba Asteion Super-4, 64-х срезовом КТ Toshiba Aquilion 64, MPT Philips Intera 1,5T. Практически у всех пациентов заключения были верифицированы. У всех больных обследовались органы брюшной полости, забрюшинного пространства. Обследования проводились многократно: до и после химиолучевой терапии. У большинства пациентов диагнозы верифицировались гистологически.

\section{2. Результаты исследования}

Первичный опухолевый очаг при НХЗЛ развивается в любом органе, содержащем лимфоидную ткань, и чаще всего, возникает в лимфатических узлах - 48,2\%, реже в других органах: в желудочно-кишечном тракте (ЖКТ) - 13,8\%, в кольце Вальдейера - 9,2\%, в костях - 8,6\%, в коже $-7,4 \%$, в в мягких тканях - 3\%. Частота экстранодальных поражений (печень, селезенка, поджелудочная железа, почки, надпочечники варьирует в широких пределах: от 4,1\% до 48\%). КТ картина экстранодальных проявлений при НХЗЛ разнообразна и не всегда имеет весь комплекс характерных признаков.

Вместе с тем, сочетание поражения отдельных органов и увеличение лимфоузлов всегда характерно для неходжкинских лимфом [1; 4]. Так, например, при компьютерно-томографическом исследовании желудка при КТ-исследовании локальные и диффузные формы НХЗЛ выявлялись на срезах в виде утолщения (более 8 мм) и деформации стенок, как по наружному, так и по внутреннему контурам. При этом поражение желудка не всегда сопровождалось регионарной лимфоаденопатией, а чаще всего в области ворот желудка и печени определялись множественные мелкие пакеты увеличенных лимфоузлов до 6-8 мм в диаметре (рис. 1, 2). 

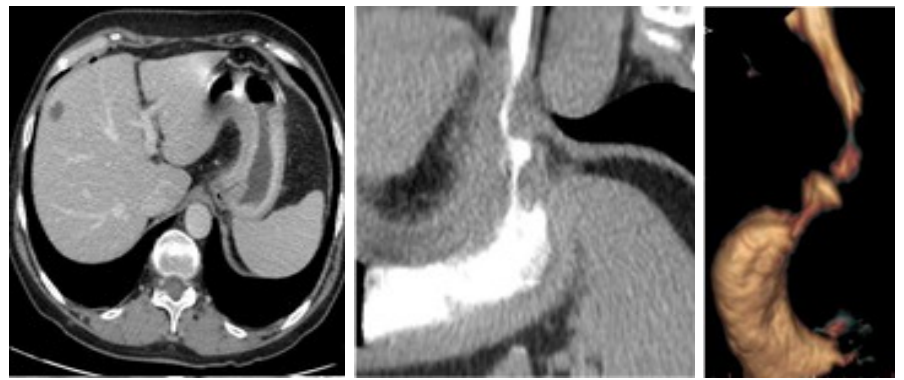

Pис. 1. На серии сканов выраженная инфильтраџия слизистой оболочки и подслизистого слоя абдоминального отдела пищевода, кардиального и субкардиального отделов желудка с утолщением их. В биоптате после ЭФГДС данные в пользу МАLT-лимфомы
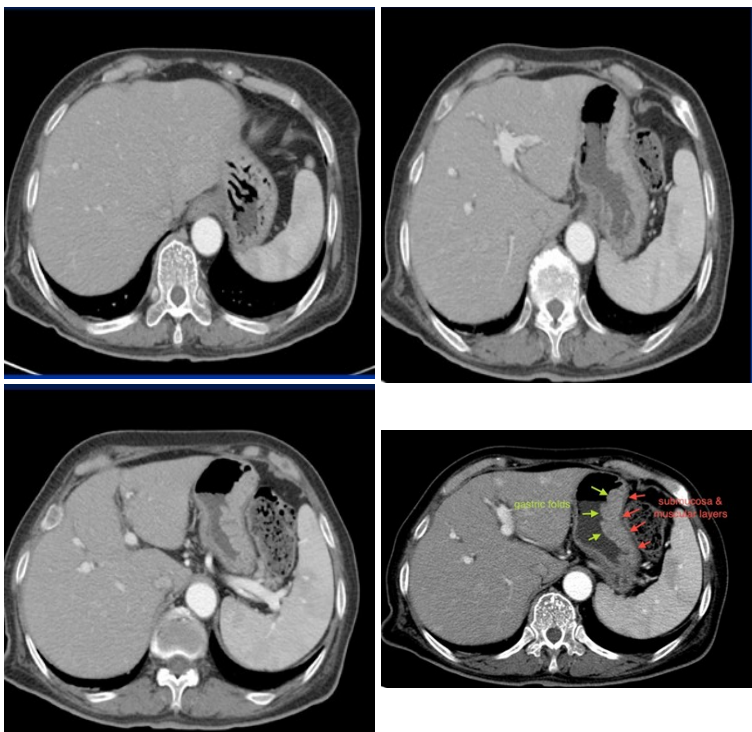

Pис. 2. На серии КТ определяется утолщение слизистой оболочки желудка, четко прослеживается граница слизистой от интактного, тонкого и ровного подслизистого и мышечного слоя. Эндоскопия-злокачественная лимфома

При поражении печени гепатомегалия обнаруживалась практически у всех больных обследуемой группы. В 60\% больных в печени выявлены очаговые изменения. Визуализировались как единичные 
так и множественные гипоинтенсивные очаги различного диаметра, чаще всего с нечеткими контурами. Плотность печени снижалась до 40-45 Ед.Н (при норме 55-60 Ед.Н).

Увеличивается в размерах также селезенка. В структуре селезенки определялись очаги разных размеров от 0.5-2.0 см до более крупных. Поверхность селезенки становилась бугристой.
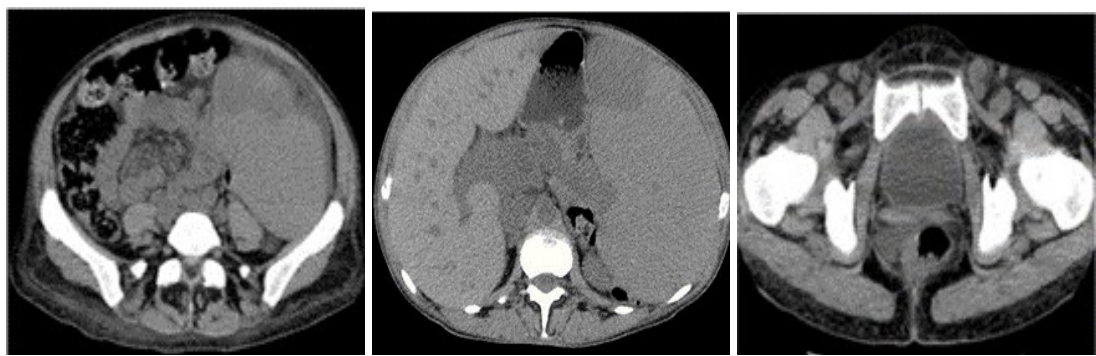

Рис. 3. Выраженная спленомегалия с многоочаговой инфильтрацией паренхимь селезенки, перилиенального пространства и брюшной стенки.

Увеличение паховых лимфоузлов с двух сторон

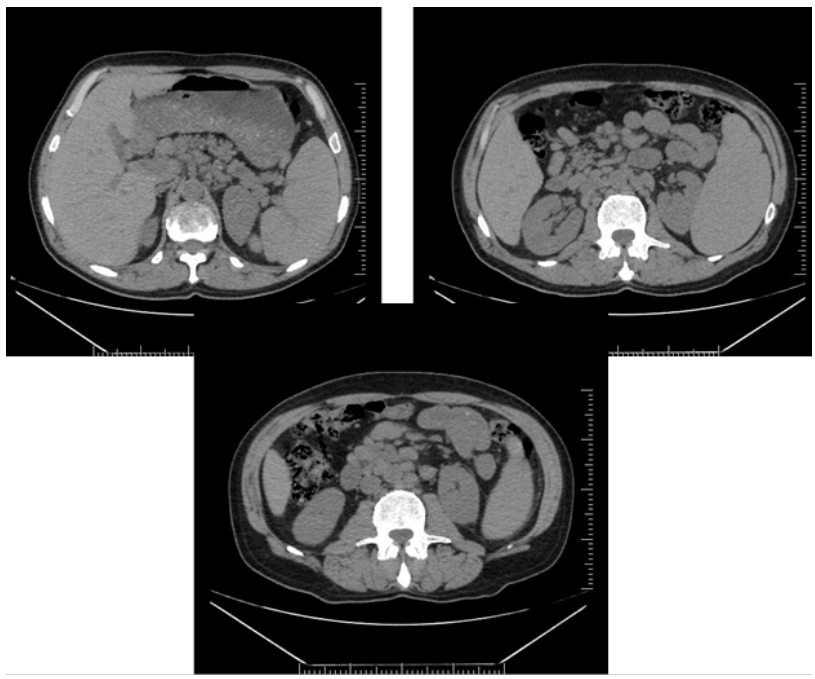

Рис. 4. Умеренная спленомегалия и поражение забрюшинных лимфоузлов и лимфоузлов ворот печени 
Значительно увеличивалась группа внутрибрюшных лимфоузлов (>1.5-2.0 см). Чаще всего они образовывали крупные конгломераты, которые располагались у ворот печени, селезенки, в парапанкреатической клетчатке, вдоль крупных сосудистых структур аорты, нижней полой и воротной вен (рис. 3,4$)$.

Пакеты л/узлов определялись также в области надпочечников и почек. При в/в контрастировании л/узлы слабо накапливали контраст. В отдельные л/узлах отмечались участки некроза, не накапливающие контраст. Иногда конгломераты л/узлов визуализировались как опухолевидное образование с бугристой поверхностью или с участками разряженных крупных конгломератов, что приводило к заметному смещению и сдавливанию сосудов брюшной полости, желудка, кишечника, мочевого пузыря. Важно подчеркнуть, что КТ позволяет выявить наиболее измененные л/узлы, определить их глубину, залегание и точное расположение, отношение к другим органам, что дает возможность более целенаправленно осуществлять локальную лучевую терапию, следить за ее эффективностью

Поражение поджелудочной железы напоминает поражение при хроническом панкреатите, но при лимфомах отмечается накопление контраста в зоне локализации опухолевого конгломерата с наличием тонкого ободка вокруг (рис. 5) [5; 6; 7]. Иногда повышение плотности отмечалось и всей ткани поджелудочной железы, что указывало на длительный прием цитостатических препаратов. Высокоэффектитвным методом оказалось КТ при вторичном поражении надпочечников у больных с НХЗЛ. При этом отмечалось увеличение размеров надпочечников, либо появление очаговых образований.

Высокоэффектитвным методом оказалось КТ при вторичном поражении надпочечников у больных с НХЗЛ. При этом отмечалось увеличение размеров надпочечников, либо появление очаговых образований. Специфические поражения почек наблюдались в незначительном проценте пациентов. При этом обнаруживалось увеличение размеров органа, либо определялись очаги, различные по плотности. Зачастую вблизи пораженного органа регистрировались увеличенные лимфоузлы.

Более четко КТ дает возможность выявить опухолевое поражение кишечника [8]. Лимфома кишечника представляет собой неод- 

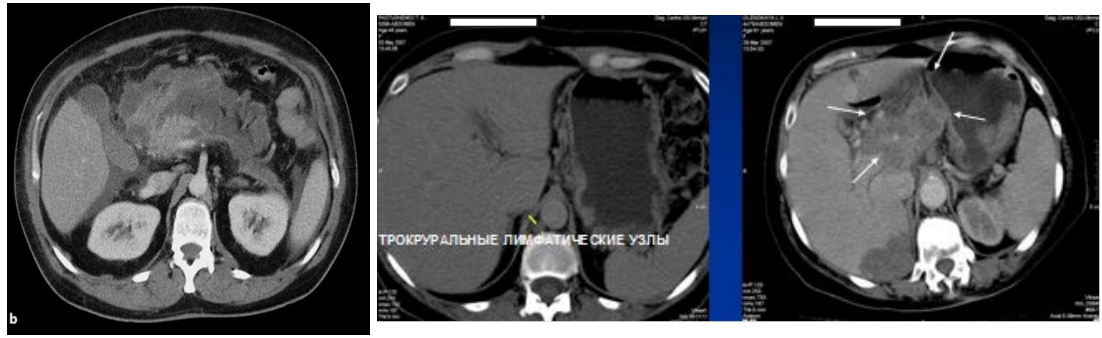

Рис. 5. Поражение поджелудочной железы
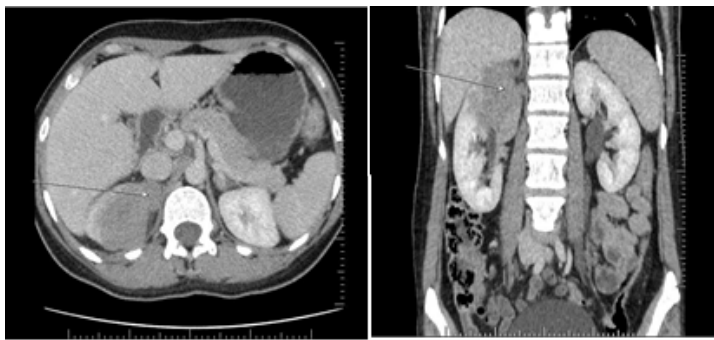

Puc. 6. После внутривенного болюсного контрастирования в верхнем сегменте правой почки массивный участок лимфоидной инфильтрации

с нечеткими контурами, не накапливающий контрастное вещество, рапространяющийся в перилиенальное пространство

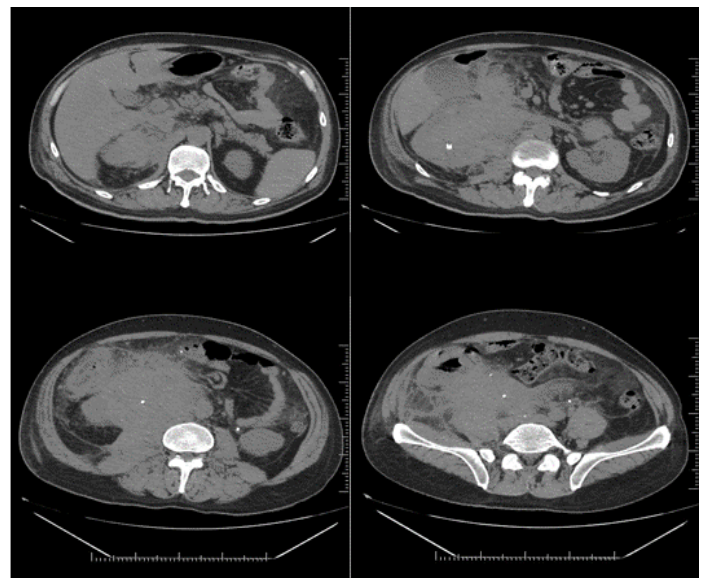

Рис. 7. Тот же пацииент после курса химиотерапии через 3 недели 

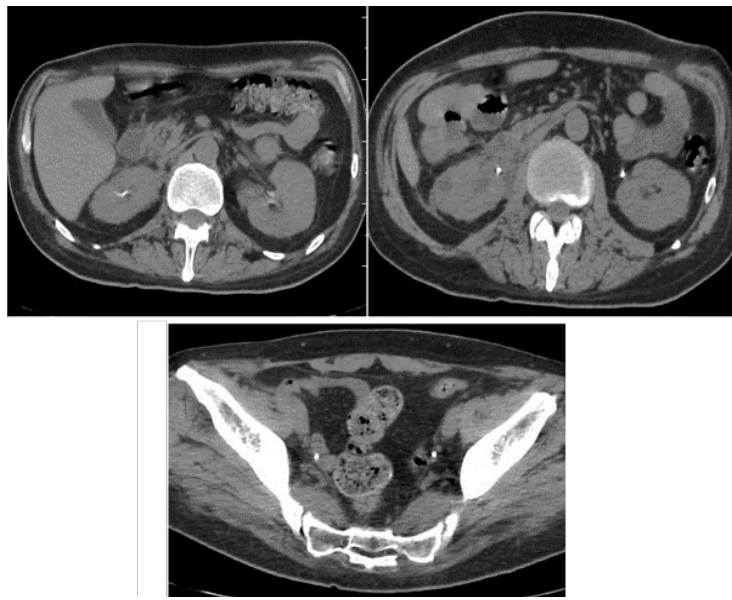

Рис. 8. На серии КТ отмечается массивная пролиферация лимфоидной ткани забрюшинного пространства, полости таза и подвздошной области справа, а также солидное мягкотканное образование периренального пространства слева

нородное образование различных размеров и плотности. Она развивается из лимфоидной ткани подслизистого слоя стенки кишки, прорастает в слизистую оболочку с образованием язв и также может прорастать в серозную оболочку. Поскольку лимфома характеризуется местным инвазивным ростом, она часто метастазирует в регионарные лимфатические узлы, затем в селезенку и более отдаленные области (рис. 9).
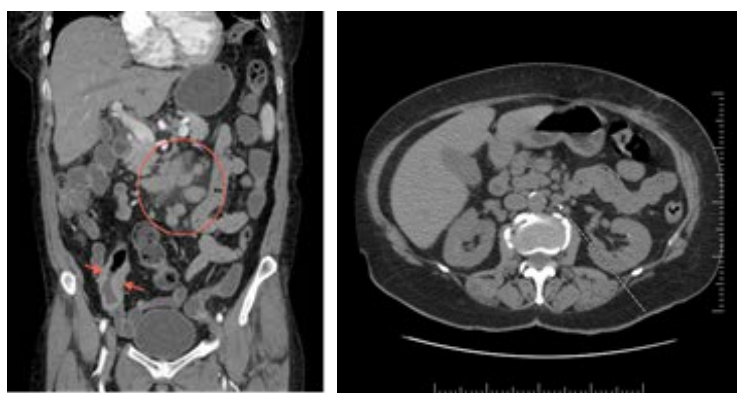

Pис. 9. Увеличение лимфоузлов брыжейки,

поражение слепой кишки и увеличение забрюшинных лимфоузлов 
В ходе обследования пациентов с НХЗЛ определялась эффективность проводимой терапии. Нами было установлено, что 1/3 пациентов достаточно было 2-3 курсов химиотерапия для уменьшения л/узлов. Однако, в целом необходимо проводить 5-6, а иногда и 8 курсов химиотерапии, а некоторым пациентам проводить локальную лучевую терапию (рис. 10).
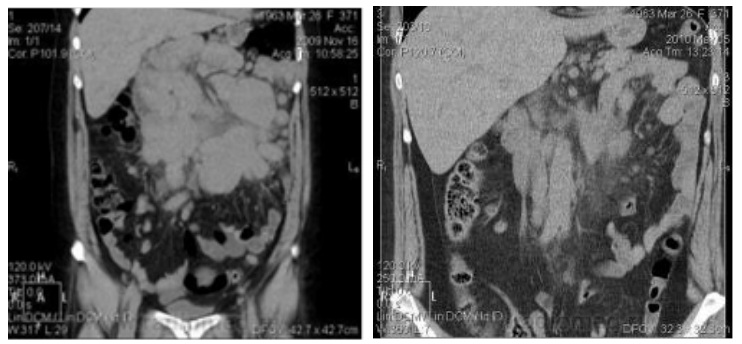

Pис. 10. Состояние лимфоузлов до и после курса лучевой терапии

При НХЗЛ в опухолевый процесс может вовлекаться плевра. Чаще всего скопление жидкости в плевральной полости, наблюдается у пациентов с часто рецидивирующим процессом и генерализацией опухолевого процесса. Кроме того, жидкость может наблюдаться в перикарде (рис. 11, 12).
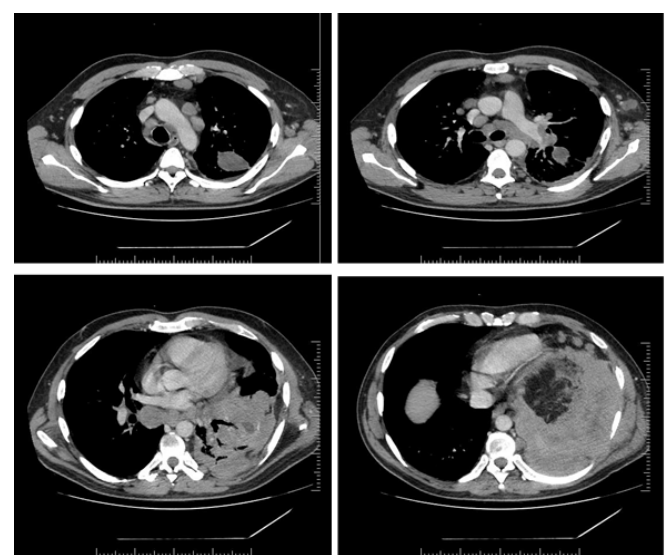

Puc. 11. Распространенный лимфопролиферативный прочесс грудной клетки с контактным поражением плевры, легких, лимфоузлов средостения и левой аксиальной области, перикарда 

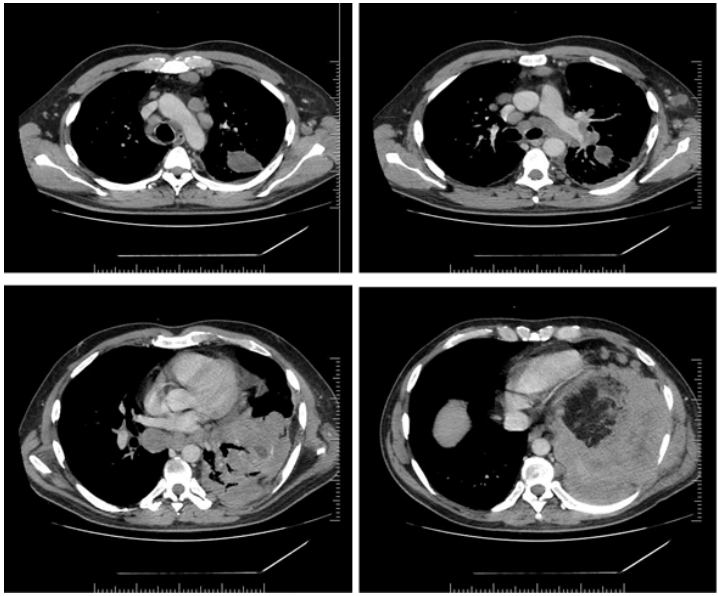

Рис. 12. Тот же пациент - поражение диафрагмы, желудка, пищевода, тонкой и толстой кишки, брюшной стенки. Состояние после спленэктомии и резекции кишечникаПри этом следует обратить внимание на наличие увеличенных л/узлов в средостении и на специфическое поражение легочной ткани [1]. Наличие жидкости в плевре и перикарде говорит о плохом прогнозе. У пациентов НХЗЛ

в брюшной полости также нередко определяется асиитическая жидкость
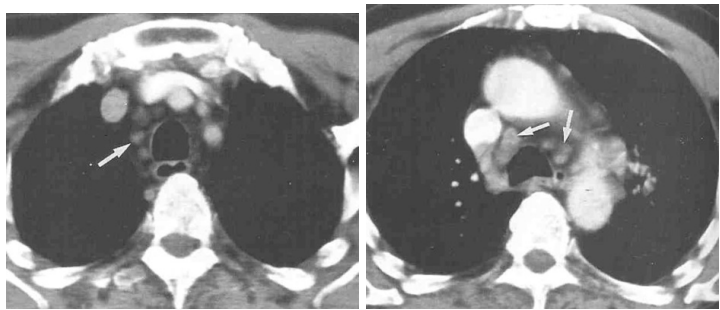

(a) Паратрахеальные л/y

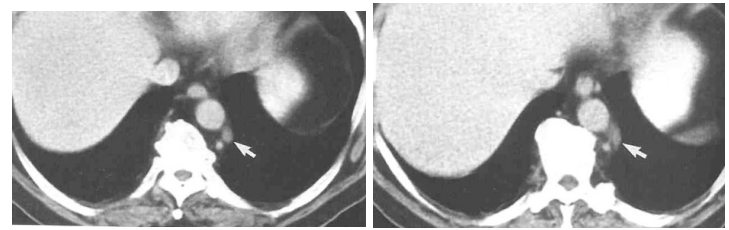

(b) Ретрокруральные л/у

Рис. 13. Лимфома Ходжкина 


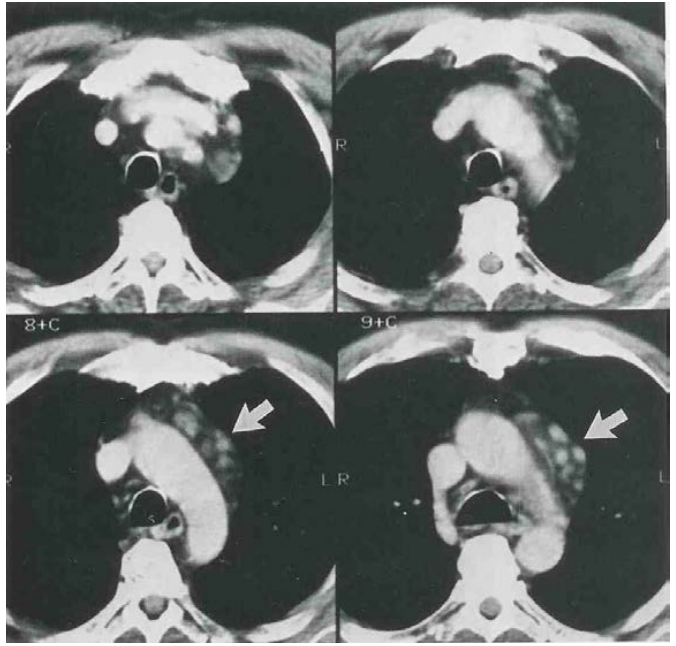

Pис. 14. Лимфома Ходжкина. Увеличенные периваскулярные л/у

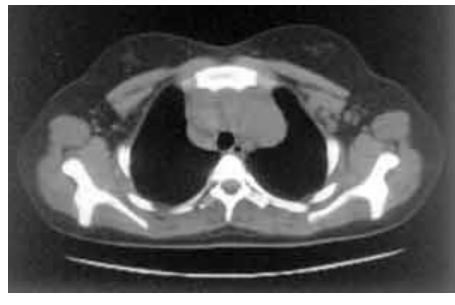

(a) КТ без усиления.

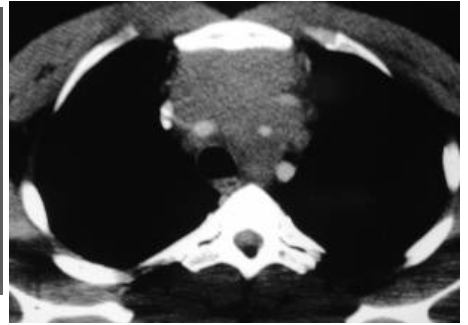

(b) КТ с усилением.

Конгломерат ретростернальных л/y. Переднее средостение

Рис. 15. Лимфома Ходжкина
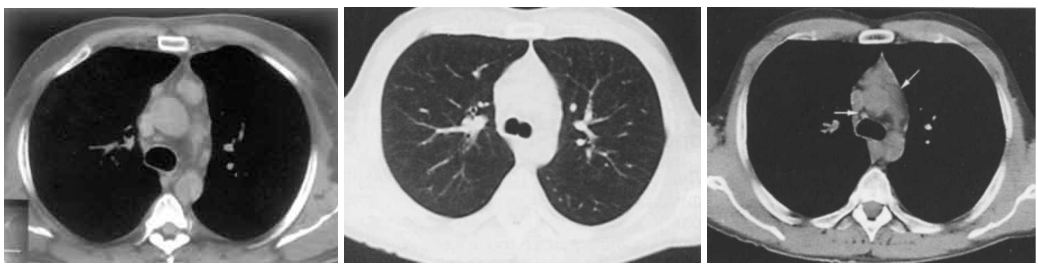

Pис. 16. Лимфома Ходжкина: (а) Преваскулярные. лимфоузль;

(b) медиастинальная форма (<легочный> режим); (c) Медиастинальная форма верхнее средостение. Множество увеличенных л/у (мягкотканый режим) 


\section{Chapter «Medical sciences»}

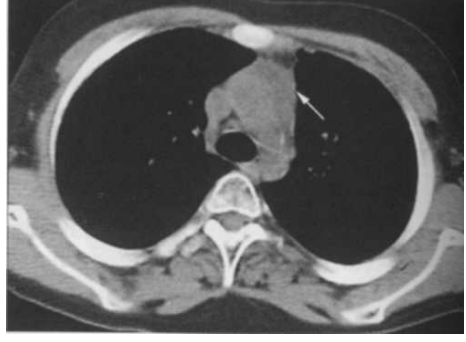

Пакет лимфоузлов плохо дифференцируемьх между собой (между дугой аортьл и медиастинальной плеврой)

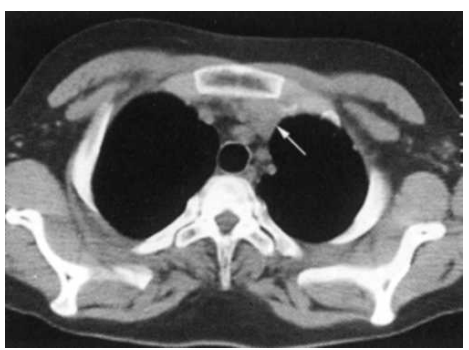

(a) медиастинальная форма, верхнее средостение

Pис. 17. Лимфома Ходжкина
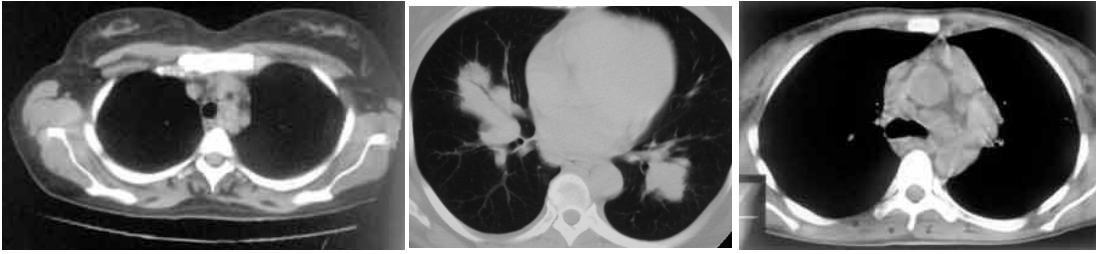

(a) Паратрахеальные лимфатические узль; (b) Бронхопульмональные лly;

(c) Трахеобронхиальные и бифуркационные лимфатические узль с компрессией и деформацией трахеи (средостение расширено)

Pис. 18. Лимфома Ходжкина

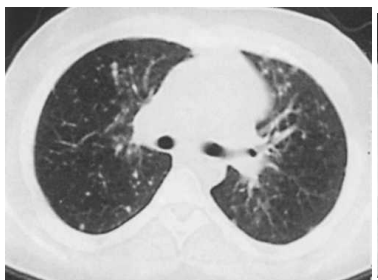

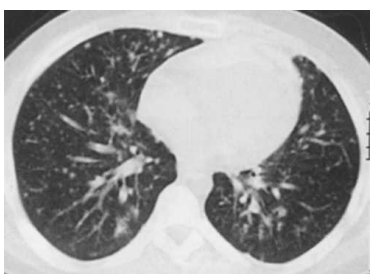

a

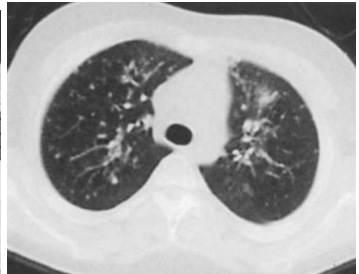

b

(a) Увеличенные, с тенденичией к слиянию медиастинальные л/y, гранулемы в легочной ткани; (b) Легочный рисунок усилен, деформирован.

В легких множество мелкоочаговых образований округлой формы мягкотканой плотности с четкими ровныли контурами.

Pис. 19. Лимфома Ходжкина. Медиастинально-легочная форма 
Viktor Sokolov, Alexander Korsun

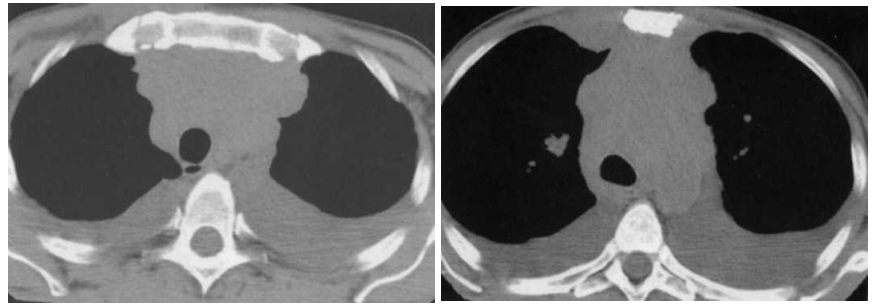

Puс. 20. Лимфома Ходжкина. Нативная КТ
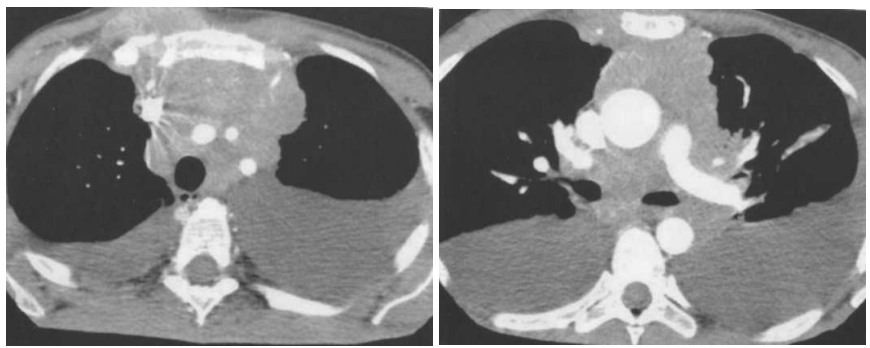

Pис. 21. Лимфома Ходжкина. МСКТ-ангиография. Распространение новообразования на переднее, среднее и заднее средостение
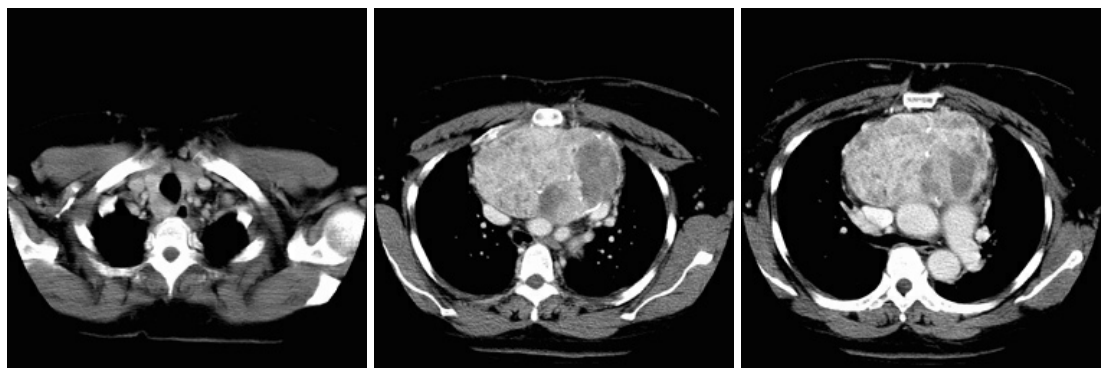

Рис. 22. Пациентка К., 55 лет. Диагноз: Сr ЩЖ, Пер.-ср. зоб

Полученные данные: Большая неоднородная хорошо ограниченная масса в переднем средостении с областями обызвествления. Дифф. диагноз: Тимома и Тератома 
Chapter «Medical sciences»

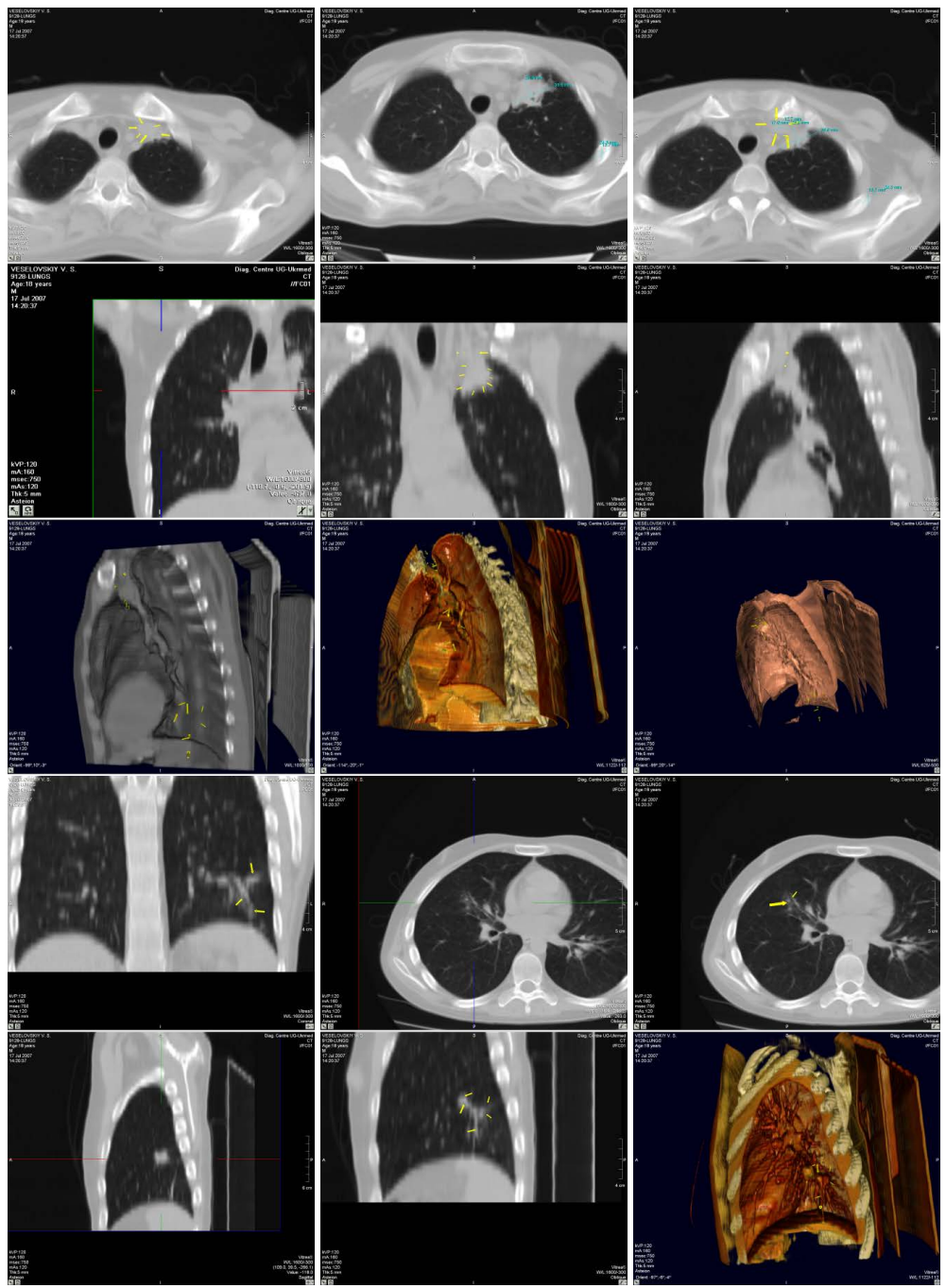

Рис. 23. Лимфома Ходжкина. После 9 сеансов химио-лучевой терапии

Медиастинально-легочная форма. Наличие остаточных масс.

Виртуальная реконструкция. Фиброзные тяжи в легочной ткани (постлучевой синдром) 


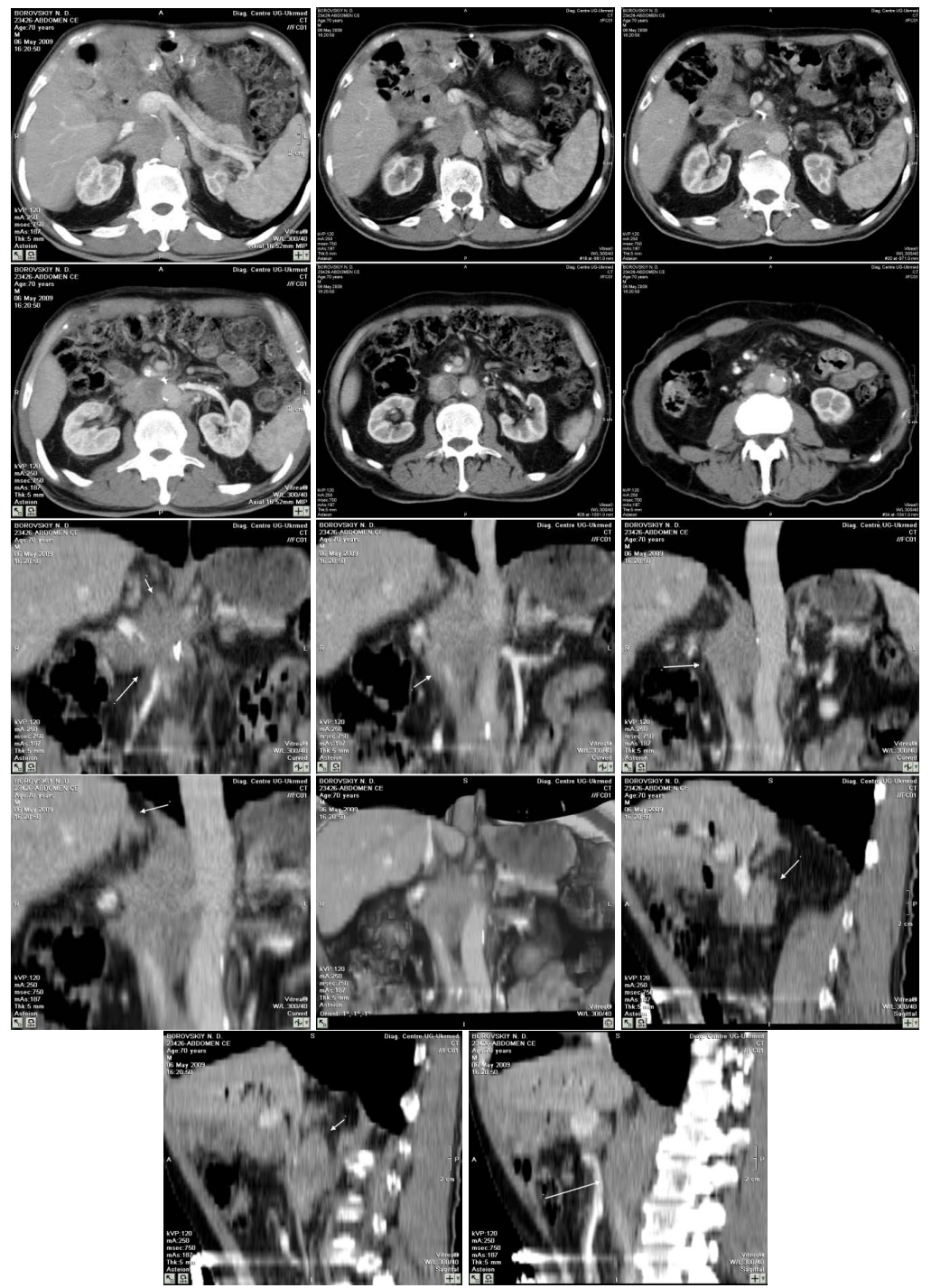

Pис. 24. Лимфаденопатия в области удаленного новообразования головки поджелудочной железы. Увеличение л/у верхней поясничной группь

Аксиальная и косая корональная реконструкция 


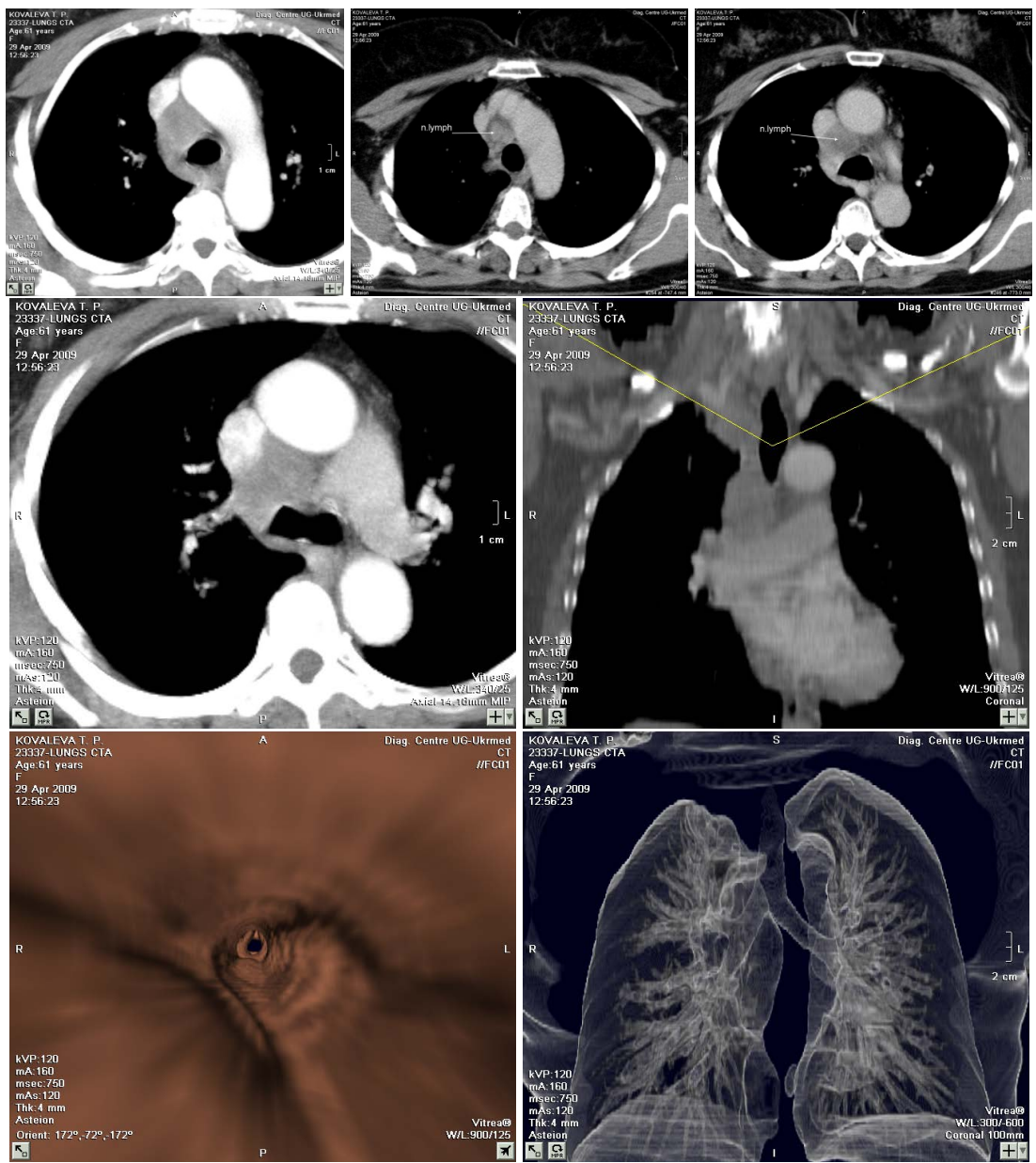

(a) Виртуальная бронхоскопия. Признаки компрессии трахеи

(b) Объемная реконструкция в режиме воздушной ткани.

Pис. 25. Увеличенные л/у аортального окна (гомогенное мягкотканое образование). Рак верхушки легкого опухоль Панкоста. Компрессионный синдром 
Viktor Sokolov, Alexander Korsun

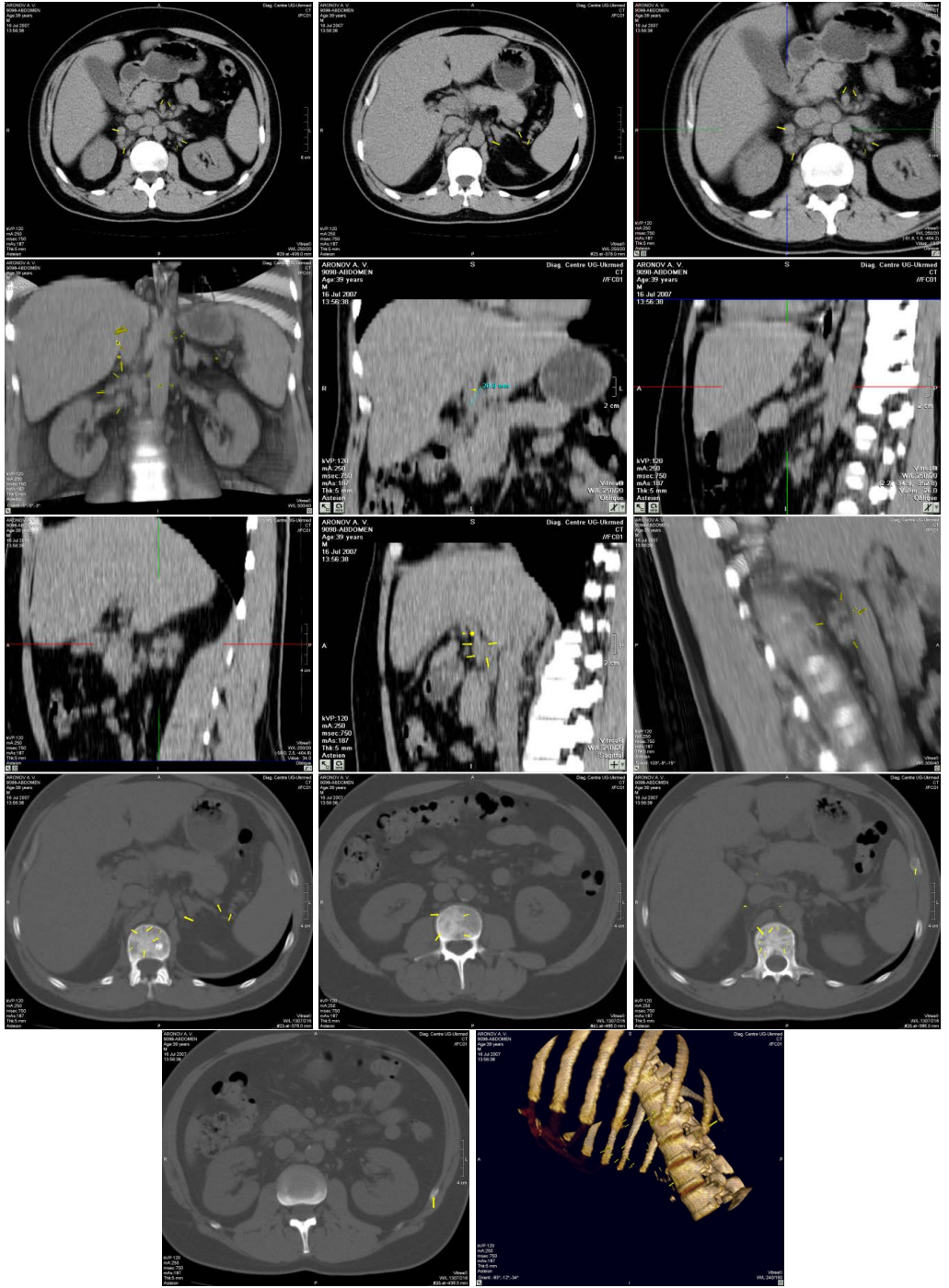

Рис. 26. Лимфома Ходжкина (контроль после химио-лучевой терапии). Увеличены поясничные и межкишечные группы л/у. Конгломераты увеличенных л/у в области нижней полой вены и парааортально. Очаги деструкции смешанного типа в телах позвонков и в ребрах 


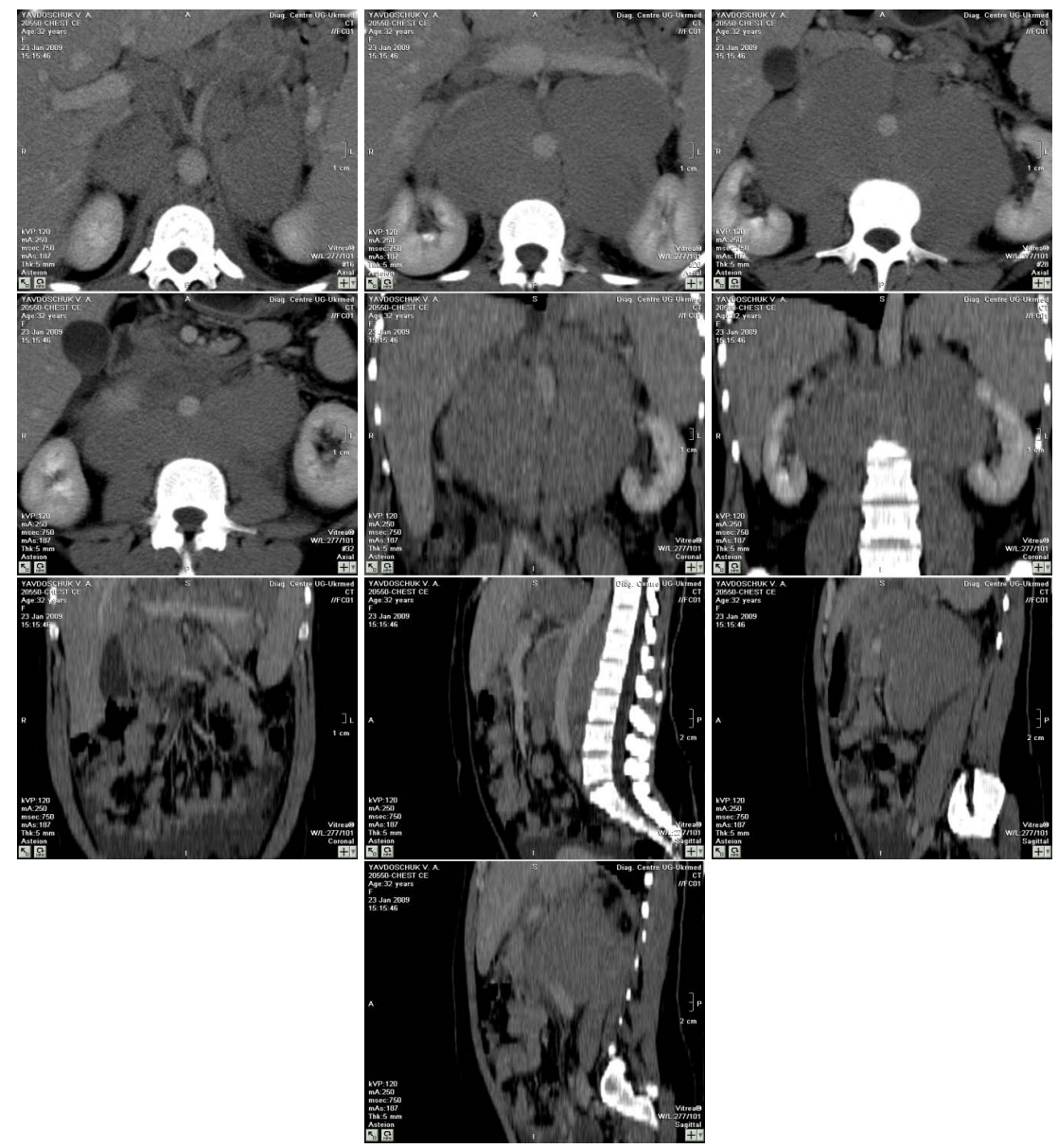

Pис. 27. Лимфома Ходжкина.

Поражение забрюшинных и ретрокруральных л/y 

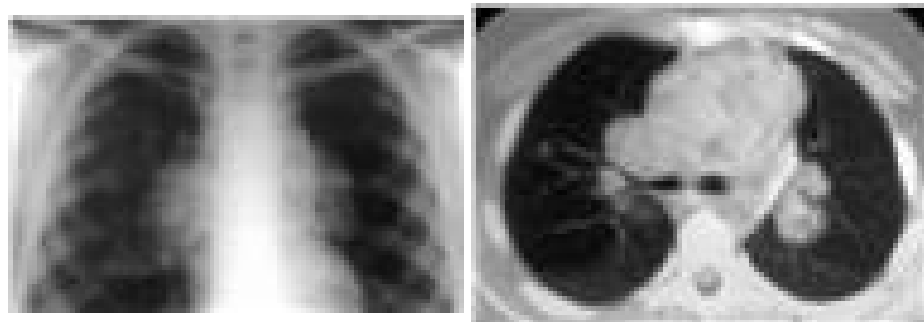

Рис. 28. Рентгенография ОГК - первичный метод исследования при болезни Ходжкина, на котором выявляется корневая и средостенная лимфаденопатия у 60\% пачиентов, иногда с компрессией или смещением трахеи
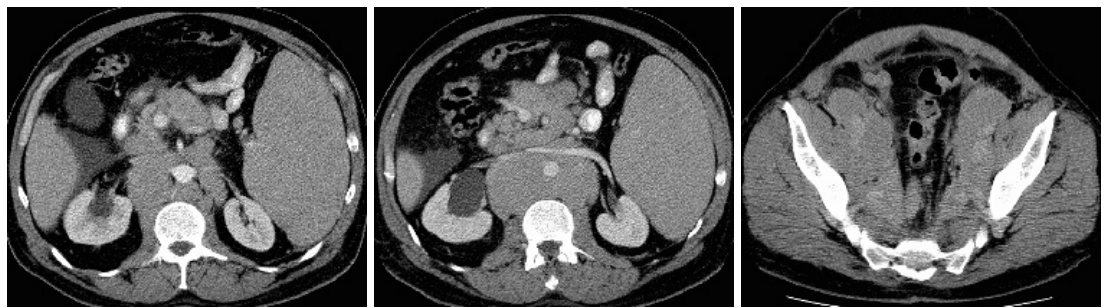

Pис. 29. Больной М., 72 лет. Диагноз: Низкодифференцированная злокачественная лимфома. Полученные данные: спленомегалия, асиит. Обширное поражение брюшных, тазовых и парааортальных л/y, вовлекающее в прочесс н.полую вену и мочеточники, распространяющееся в таз с вовлечением обеих подвздошных областей. Гидронефроз справа
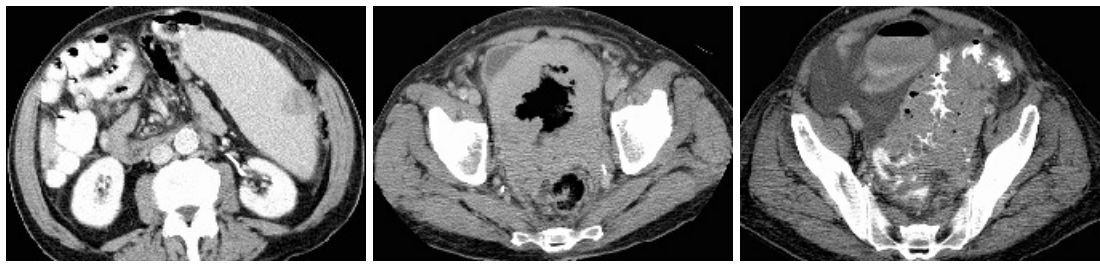

Pис. 30. Мужчина 65 лет Диагноз: Неходжкинская лимфома, вдавление сигмы в селезенку, кишечно-пузырная фистула

Селезенка увеличена (вдавление петли сигмовидной кишки). В малом тазу образование пониженной плотности 11 х 10 см, содержащее некротические массы Асцит. Ретрокруральная и парааортальная лимфоаденопатия. 
В сигме и в мочевом пузыре - наличие газа. Фистула диагностируется по косвенным признакам: свободная жидкость в малом тазу, в мочевом пузыре и в сигме.
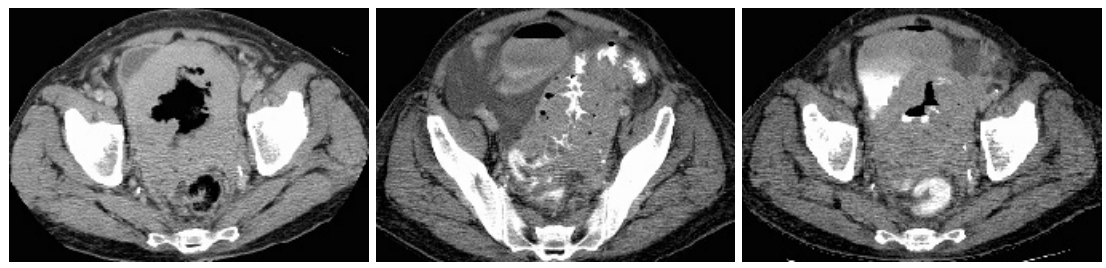

Puс. 31. Мужчина 65 лет. Диагноз: Неходжкинская лимфома, вдавление сигмы в селезенку, кишечно-пузырная фистула

Селезенка увеличена (вдавление петли сигмовидной кишки). В малом тазу образование пониженной плотности 11 х 10 см, содержащее некротические массы Асцит. Ретрокруральная и парааортальная лимфоаденопатия. В сигме и в мочевом пузыре - наличие газа. Фистула диагностируется по косвенным признакам :свободная жидкость в малом тазу, в мочевом пузыре и в сигме.
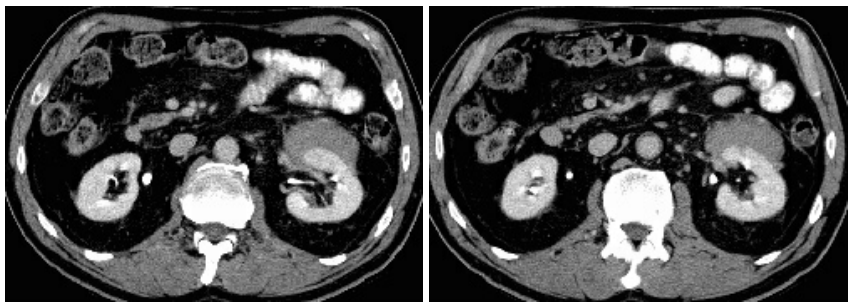

Рис. 32. Диагноз: высокодифференцированная В-клеточная паранефральная лимфома. По передней поверхности левой почки отмечается наличие мягкотканого компонента размерами $2.4 \mathrm{~cm} n / 3 \times 6.0 \mathrm{~cm} \kappa / \kappa$. В аорте кольиевидный тромб

Неходжкинская лимфома поджелудочной железы может выглядеть на КТ, как одна из следующих форм:

1. Диффузное увеличение ПЖ.

2.Диффузное увеличение ПЖ с множественными гиподенсными массами. 
3. Мягко-тканная масса с четким контуром.

4. Масса с кистозной областью в центре и уплотнением по контуру (рис. 33).

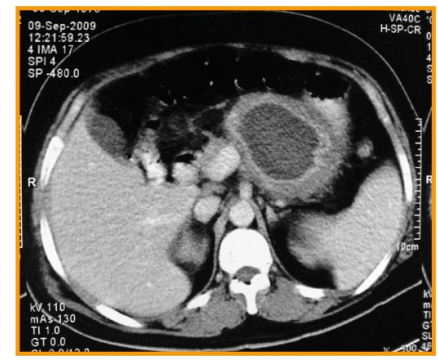

Рис. 33. Лимфома поджелудочной железы (ЛПЖ). Гистологически подтвержденная НХЛ поджелудочной железь; крупноклеточный вид
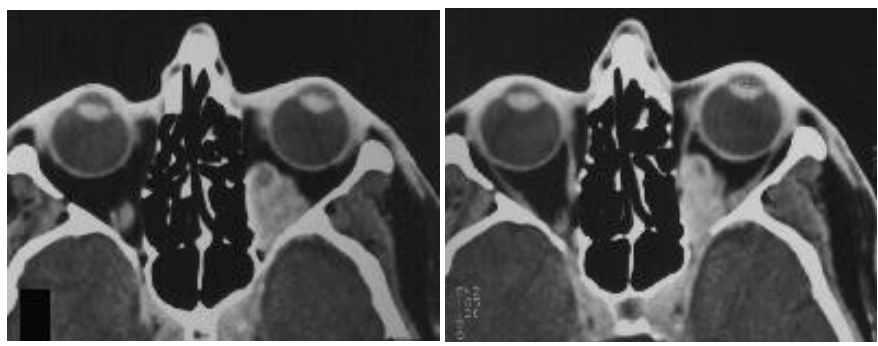

Рис. 34. Лимфома орбиты. Пациент К., 66 лет с пониженной остротой зрения В интракорональной области левой орбиты визуализируется мягкотканое образование низкой плотности без очагов обызвествления и распространения на костные структуры
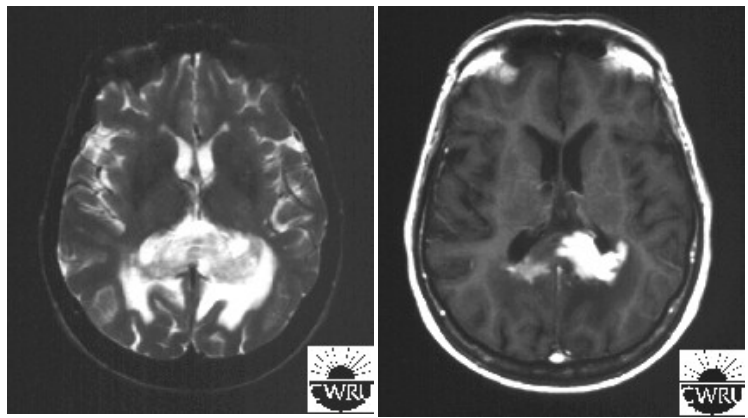

Pис. 35. МРТ T1 и Т2-ВИ с контрастным усилением. Первичная церебральная лимфома. Паииентка С., 79 лет (3 недели дезориентации) 
Отек в обеих заднетеменных и затылочных областях, с вовлечением мозолистого тела. Интенсивное накопление контраста в области поврежденного мозолистого тела. Дифференциальный диагноз с глиобластомой.

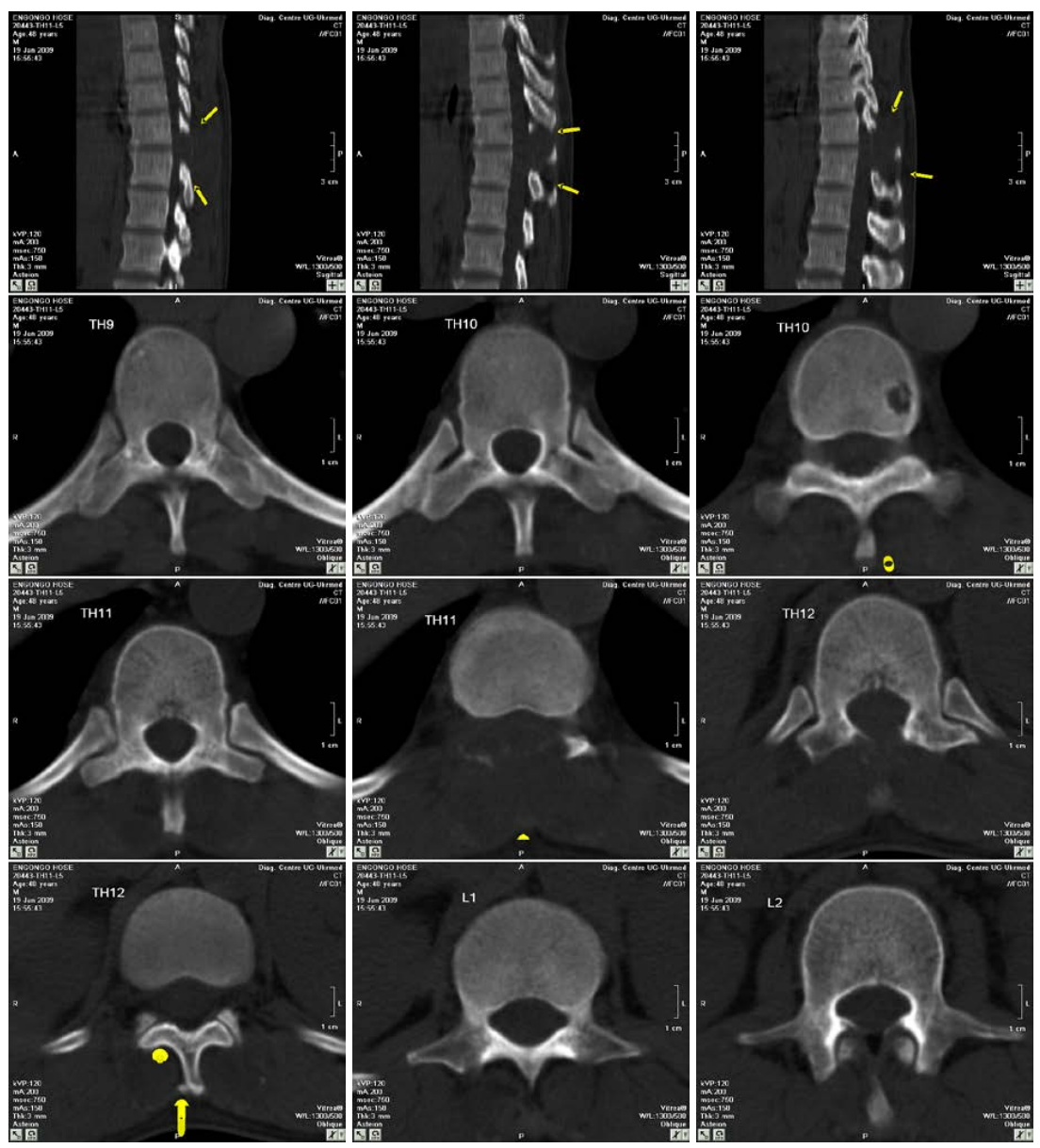

Рис. 36. Злокачественная лимфома (впервые выявленная).

Экстранодальное поражение. Очаги деструкиии смешанного характера в телах позвонков 

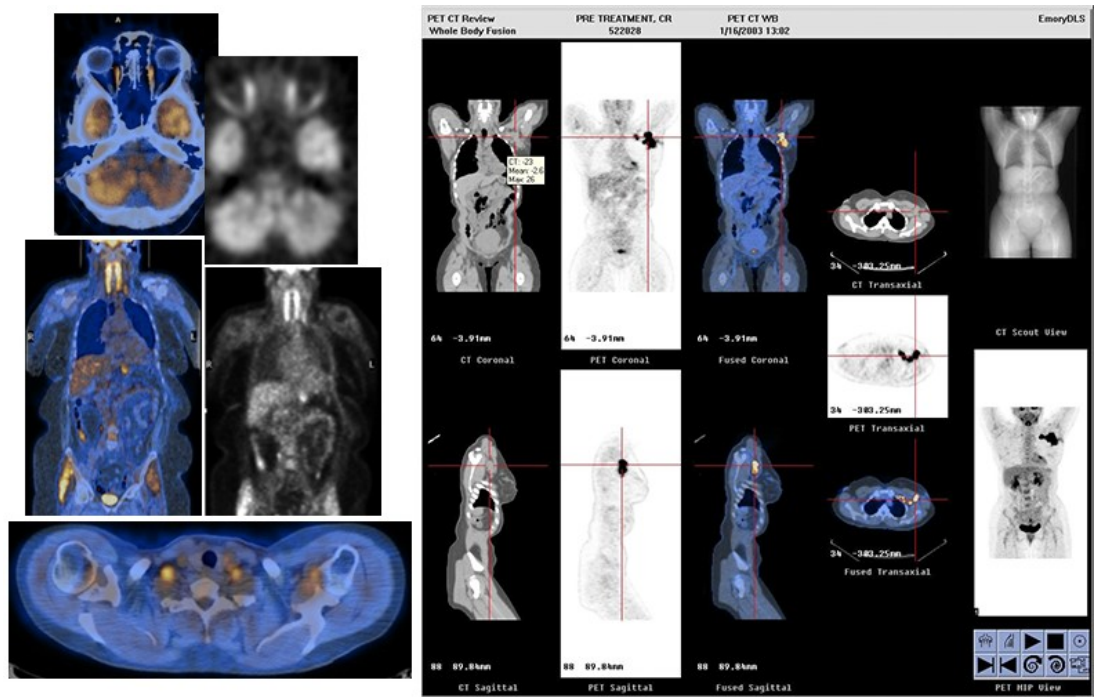

Рис. 37. Накопление радионуклида в пораженных лимфоузлах

\section{3. Выводы}

При неходжкинских хронических злокачественных лимфомах (НХЗЛ) в патологический процесс вовлекаются многие органы и системы. Наиболее сложная диагностика этих заболеваний у ВИЧ-инфицированных лиц, т.к. происходит вовлеченние в опухолевый процесс печени, поджелудочной железы, селезенки, кишечника, надпочечников и органов малого таза, а также различных групп лимфатических узлов.

КТ является одним из ведущих методов диагностики НХЗЛ. Его высокая информативность позволяет рекомендовать СКТ в качестве основного метода диагностики пораженных абдоминальных лимфоузлов и паренхиматозных органов. При выявлении пакетов увеличенных л/узлов обязательно следует проводить осмотр прилежащих органов: печени, селезенки и др. органов; определять их размер, плотность. Увеличенные л/узлы чаще всего располагаются вдоль крупных сосудов и ворот печени, селезенки, почек. Важную диагностическую информацию КТ дает при других экстранодальных локализациях НХЗЛ, в т.ч. желудочно-кишечного тракта, плевры, перикарда, легких. 
Применение СКТ позволяет также определить эффективность проводимого лечения (химиои лучевой терапии).Оценивая чувствительность и специфичность данных КТ, можно отметить чувствительность в оценке состояния абдоминальных лимфоузлов равной $96 \%$, а специфичность-92\%.

КТ картина экстранодальных проявлений при НХЗЛ разнообразна и не всегда имеет весь комплекс характерных признаков. Вместе с тем, сочетание поражения отдельных органов и увеличение лимфоузлов всегда характерно для неходжкинских лимфом. Так, например значительно увеличивалась группа внутрибрюшных лимфоузлов (>1.5-2.0 см). Чаще всего они образовывали крупные конгломераты, которые располагались у ворот печени, селезенки, в парапанкреатической клетчатке, вдоль крупных сосудистых структур аорты, нижней полой и воротной вен.

\section{Список литературы:}

1.В.Н.Соколов, Е. Овчаренко, Г. Рожковская, Т. Дорофеева, В. Цвиговский, Л. Анищенко, Е. Ситникова, Ю. Стасюк, А. Мудрова и Е. Костов, “Рентгенотомографическая картина лимфопролиферативных заболеваний”. Променева діагностика, променева терапія. № 1-2. С. 51-56. 2013.

2. S. B. Edge, D. R. Byrd, M. A. Carducci, C. C. Compton, A. Fritz, F. Greene и др., AJCC cancer staging manual. Springer New York, 2010, т. 7.

3. S. M. Ansell. "Hodgkin Lymphoma: Diagnosis and Treatment", Mayo Clinic Proceedings, т. 90, № 11, с. 1574-1583, нояб. 2015, issn: 0025-6196. doi: 10.1016/j.mayocp.2015.07.005. url: https://doi.org/ 10.1016/j.mayocp.2015.07.005 2006.

4. M. W. Saif. “Primary pancreatic lymphomas”, Jop, т. 7, № 3, c. 262-273,

5. И. Поддубной и В. Савченко. Российские клинические рекомендации по диагностике и лечению лимфопролиферативных заболеваний, 2016.

6. P. S. Grimison, M. T. Chin, M. L. Harrison и D. Goldstein. "Primary pancreatic lymphoma-pancreatic tumours that are potentially curable without resection, a retrospective review of four cases”, $B M C$ cancer, т. 6, № 1, c. 117, 2006.

7. И. Маев, А. Трухманов, В. Доронин и Ю. Кучерявый, "Первичная панкреатическая лимфома". Российский журнал гастроэнтерологии, гепатологии, колопроктологии. Т. 18. № 3. С. 48-62. 2008.

8. Y. J. Wang, C. M. Jeng, Y. C. Wang, P. P. Chang и T. H. Wang. "Primary pancreatic Burkitt's lymphoma mimicking carcinoma with obstructive jaundice and very high CA19-9", European journal of gastroenterology \& hepatology, т. 18, № 5 , c. 537-540, 2006. 


\section{References:}

1. V. N. Sokolov, E. Ovcharenko, G. Rozhkovskaya, T. Dorofeeva, V. Tsvigovsky, L. Anischenko, E. Sitnikova, Yu. Stasyuk, A. Mudrova and E. Kostov. "X-ray tomography picture of lymphoproliferative diseases", Promeneva diagnostics, promeneva therapy, No. 1-2, p. 51-56, 2013.

2. S. B. Edge, D. R. Byrd, M. A. Carducci, C. C. Compton, A. Fritz, F. Greene et al., AJCC cancer staging manual. Springer New York, 2010, v. 7.

3. S. M. Ansell. "Hodgkin Lymphoma: Diagnosis and Treatment", Mayo Clinic Proceedings, vol. 90, No. 11, p. 1574-1583, Nov 2015, issn: 0025-6196. doi: 10.1016/j.mayocp.2015.07.07.005. url: https://doi.org/10.1016/j.mayocp. 2015.07.07.005.

4. M. W. Saif. "Primary pancreatic lymphomas", Jop, T. 7, No. 3, p. 262-273, 2006.

5. I. Poddubnoy and V. Savchenko, Russian clinical guidelines for the diagnosis and treatment of lymphoproliferative diseases, 2016.

6. P. S. Grimison, M. T. Chin, M. L. Harrison and D. Goldstein. "Primary pancreatic lymphoma - pancreatic tumors that are potentially curable without resection, a retrospective review of four cases", BMC cancer, vol. 6, No. 1, p. 117, 2006.

7. I. Maev, A. Trukhmanov, V. Doronin and Yu. Kucheryavyi. "Primary Pancreatic Lymphoma", Russian Journal of Gastroenterology, Hepatology, Coloproctology, vol. 18, No. 3, p. 48-62, 2008.

8. Y.J. Wang, C.M. Jeng, Y.C. Wang, P.P. Chang and T.H. Wang. "Primary pancreatic Burkitt's lymphoma mimicking carcinoma with obstructive jaundice and very high CA19-9", European journal of gastroenterology \& hepatology, vol. 18, No. 5, with. 537-540, 2006. 